\title{
TENTACULITES ITACURUBIENSIS n.SP., DOS DEPÓSITOS REGRESSIVOS DO PARAGUAI ORIENTAL, SILURIANO INFERIOR DA BACIA DO PARANÁ*
}

\author{
JOSÉ HENRIQUE GODOY CIGUEL**
}

\begin{abstract}
TENTACULITES ITACURUBIENSIS n.sp. OF REGRESSIVE DEPOSITS FROM THE EASTERN PARAGUAY, LOWER SILURIAN OF THE PARANA BASIN. Paraguayan tentaculitids from the Cariay Formation, the upermost unit of the Itacurubi Group, eastern Paraguay, have been previously assigned to T. crotalinus, T. jaculus, T. stubeli, and T. trombetensis. However, on the basis of the analysis of ring ornamentation, heterotransversal rings, growth angle, ornamentation, and size of the external shell molds, it is possible to place them within a distinct new species Tentaculites intacurubiensis. Evidence for a probable late Ordovician through Early Silurian age range is provided by faunal data from the Itacurubi Group. These data include Climacograptus inootatus brasiliensis, Diplograptus modestus, Monograptus gregarius, and Arthrophycus alleghaniensis besides homology of Paraguay trilobites to Eohomalonotus, and close biogeographic affinity of the associated fauna to the Silurian Malvinokaffric Realm. The stratigraphic position of the fossiliferous beds is also consistent with the chronostratigraphy suggested by the fossil assemblage. The Paraguayan tentaculitids clearly differ from those found in Devonian strata outcropping on the eastern flank of the Parana Basin. The above mantioned morphological features of the shell closely resemble those of forms occuring worldwide in the Ordovician and Silurian. T. itacurubiensis n.sp. occurs in the Monograptus gregarius zone, of Llandoverian age. Thus, the presence of T. intacurubiensis n.sp. in the Parana Basin and T. trombetensis CLARKE, 1899 in the Amazon Basin is suggestive of the downward extension of the range of the Order Tentaculitida in South America to the Llandoverian (Early Silurian).
\end{abstract}

INTRODUÇÃO A fauna do Grupo Itacurubi, ocorrente no leste do Paraguai, é bastante diversificada. A associação de graptozoários com icnofósseis e o caráter primitivo dos invertebrados marinhos têm posicionado essa unidade no Siluriano, conforme Harrington (1950), Turner (1960) ou Wolfart (1961).

Os tentaculitídeos do Grupo Itacurubi foram descritos e figurados por Harrington (1950), Wolfart (1961) e Putzer (1962). Beder \& Windhausen (1918) e Harrington (1956, 1972) referem-se à presença desses fósseis coniformes com breve descrição. Esses autores relataram a ocorrência de Tentaculites crotalinus, Tentaculites jaculus, Tentaculites stubeli e Tentaculites trombetensis. No entanto, essas quatro espécies são distintas dos tentaculitídeos paraguaios, que não comportam nenhuma dessas denominações especifficas.

Harrington (1972) sugere uma possível distinção morfologica dos tentaculitídeos paraguaios, denominado-os Tentaculites sp. indet.aff. Tentaculites crotalinus SALTER e Tentaculites sp. indet. (= Tentaculites trombetensis WOLFART, non CLARKE, partim), ocorrentes nos afloramentos de $\mathrm{Ca}$ riay Lona e Posta Primavera. Em Cerro Aparipi, menciona a presença de Tentaculites sp. nov. (= Tentaculites trombetensis WOLFART, non CLARKE partim). Beder \& Windhausen (1918) como ocorrendo Tentaculites crotalinus em Arroyo Esteros; para Wolfart (1961) tem-se Tentaculites trombetensis em São José, Itauguá e Arroio Esteros. Putzer (1962) menciona a presença de Tentaculites trombetensis em Santa Rosa e Posta Primavera.

CONTEXTO GEOLÓGICO Em 1950, Harrington descreve duas seqüências sedimentares no leste do Paraguai sob a denominação "Série Caacupê" e "Série Itacurubi". Posteriormente (Harrington 1956), modifica as denominações atribuindo-lhes a categoria de grupo.

$\mathrm{O}$ que se verifica quanto ao Eopaleoźico paraguaio, em particular no flanco oeste da bacia, é um posicionamento cronoestratigráfico contraditório dos grupos Caacupé e, em especial, Itacurubi, que corresponde às formações Eusebio Ayala, Vargas Peña e Cariay. Clérice (1986) discute a litoestratigrafia dessas unidades com ampla abordagem de seus depósitos.

MATERIAL FOSSILÍFERO, PROCEDÊNCIA E MÉTODOS Os tentaculitídeos ocorrem em arenitos finos a médios, micáceos, de coloração avermelhada, da Formação Cariay. O material fossilifero e procedente do flanco ocidental da Bacia do Paraná (fig. 1), Paraguai oriental.

Os Tentaculites estão preservados como moldes externos, e raramente internos, nos folhelhos Vargas Peña e nos arenitos Cariay. A figura 2 refere-se ao local da coleta dos tentaculitídeos. Os espécimes foram analisados com auxílio de lupa binocular sob diversos aumentos.

\section{DESCRIÇÃO PALEONTOLÓGICA Classificação} Ciguel et al. (1984) adotam a sistemática de Lardeux (1969), que considera a classe subdividida em três ordens: Tentaculitida LJASCHENKO, 1955, Homoctenida BOUCEK, 1964, e Dacryoconarida FISHER, 1962.

Filo Mollusca

Classe Tentaculitoidea LJASCHENKO, 1957

Ordem Tentaculitida LJASCHENKO, 1955

Família Tentaculitidae WALCOTT, 1886 Gênero Tentaculites SCHLOTHEIM, 1820

* Contribuição ao Projeto № 193: Siluro-Devonian of Latin American do International Geological Correlation Programme (I.G.C.P.-Unesco), apresentado em Tacuaremb 6 (Uruguai) durante a IV Reunião Internacional do projeto

** Pós-graduando em Geologia Sedimentar e bolsista da Fundação de Amparo à Pesquisa do Estado de São Paulo (FAPESP), Departamento de Paleontologia e Estratigrafia do Instituto de Geociências da Universidade de São Paulo. Caixa Postal 20899, CEP 01498, São Paulo, SP, Brasil 


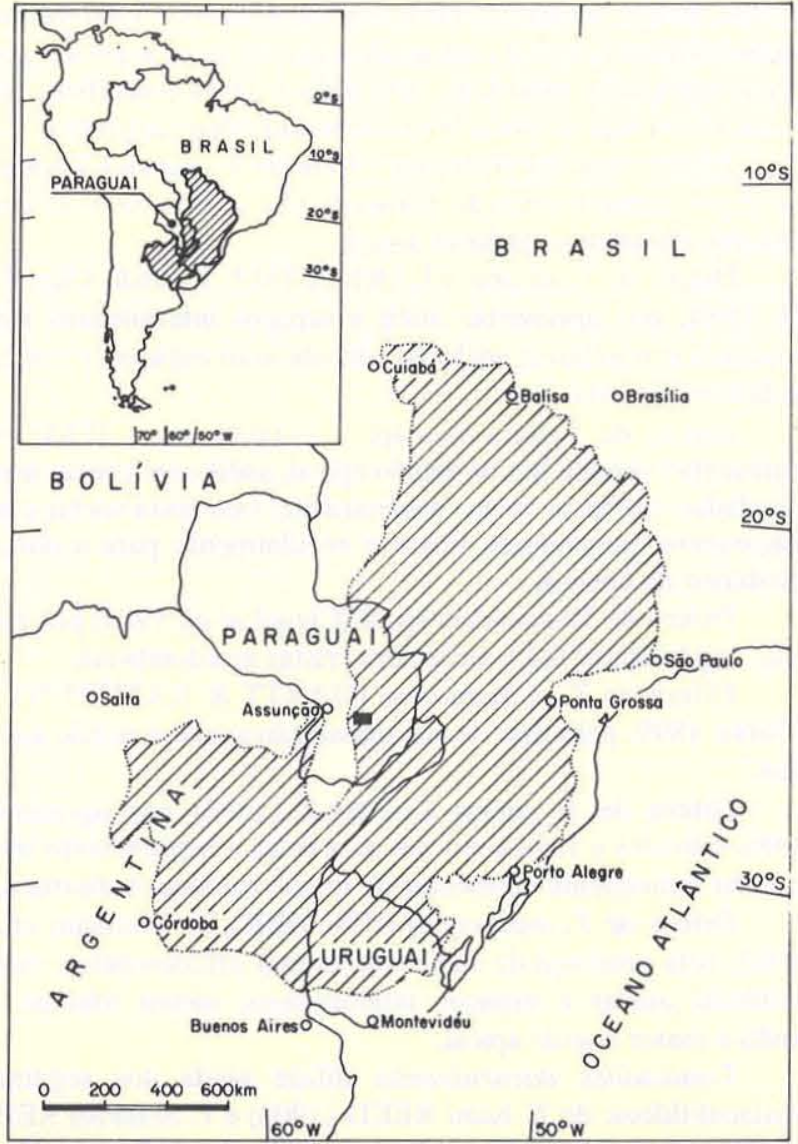

DIA COBERTURA SEDIMENTAR DA BACIA dO PARANÁ

$\square$ Procedência dos Tentaculitídeos.

Figura 1 - Localização dos depósitos do Eopaleozóico no Paraguai oriental, ressaltando a área de coleta do material fossilifero, na porção ocidental da Bacia do Paraná. Modificado de Northfleet et al. (1969)

Os tentaculitídeos provenientes do Paraguai possuem afinidade com a Família Tentaculitidae, que tem como espécie-tipo Tentaculites scalaris SCHLOTHEIM, 1820, cuja diagnose do gênero ê transcrita a partir de Lardeux (1969).

Diagnose do gênero Tentaculites Concha cônica, reta ou suavemente encurvada na região apical, comprimento médio de 15 a $30 \mathrm{~mm}$. Ornamentada com anéis regularmente desenvolvidos, relativamente espaçados da região mediana à abertura, aumentando progressivamente de tamanho. A partir de uma distância variável do ápice, os anéis são muito mais estreitos, com formato geralmente lamelar, recobrindo uma maior superfície dos espaços interanelares do que aquelas dos anéis mais espessos da região posterior. A região apical é dividida por paredes formando câmaras (meia dúzia em média), ou inteiramente obstruída por secreções calcárias. A superfície da concha é lisa na região apical e ligeiramente ondulada nas regiões mediana e da abertura. A câmara inicial é cônica, com extremidade apical afunilada e abrupta. Concha com estrutura microlamelar não perfurada.
Tentaculites itacurubiensis n. $s p$. Prancha 1 (Fotos a - f)

1918 Tentaculites crotalinus BEDER \& WINDHAUSEN (non SALTER 1856) Bol. Acad. Nac. Cienc. Cord.; v. 23; p. 259.

1950 Tentaculites crotalinus HARRINGTON (non SALTER 1856) Fac. Cienc. Exact. Contr. Cienc.; v. 1 ; p.70; est. 2; fig. 4.

1956 Tentaculites crotalinus HARRINGTON (non SALTER 1856) Mem. Geol. Soc. America; v. 65; p. 107.

1956 Tentaculites jaculus HARRINGTON (non CLARKE 1913) Mem. Geol. Soc. America; v. 65; p. 107.

1961 Tentaculites stubeli WOLFART (non CLARKE 1899) Geol. Jahrb.; v. 78; p. 57; est. 7; figs. 6-7.

1961 Tentaculites trombetensis WOLFART (non CLARKE 1899) Geol. Jahrb.; v. 78; p. 68; est. 3; figs. 7-8.

1962 Tentaculites crotalinus PUTZER (non SALTER 1856) Geol. Erde; p. 61.

1962 Tentaculites jaculus PUTZER (non CLARKE 1913) Geo. Erde; p. 61.

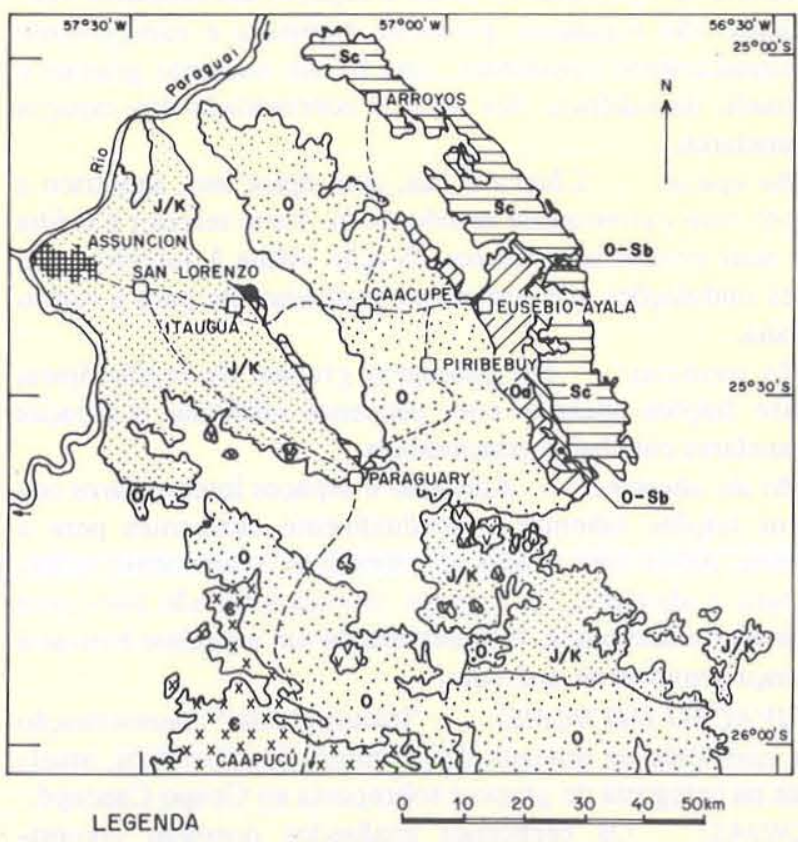

- Procedêncıa de Tentaculites ifacurubiensis n. sp.

F/K Rochas sedimentares e intrusivas pós-ITACURUBI.

Fo Formaçâo Cariay

O-sb Formaçāo Vargas Peña \} GRUPO

Fo:-1 Formaçäo Eusebio Ayala $\}$ ITACURUBI

(Siluriano Ordoviciano)

$\therefore$ Formaçōes $\left\{\begin{array}{l}\text { Tobati } \\ \text { Cerro Jhú } \\ \text { Paraguary }\end{array}\right\}$ GRUPO CAACUPE்

(Ordoviciano)

${ }^{x} x_{x}^{2}$ Rochas igneas e metamórficas pré-CAACUPÉ.

Figura 2 - Situação do Grupo Itacurubi nas proximi dades de Assunção. Os tentaculitfleos são provenientes da Formação Cariay. Mapa base no Mapa Geologico do Paraguai, apresentado na III Reunião Internacional do Projeto $n^{\text {o }}$ 193, Siluriano-Devoniano da América Latina, ocorrida em Assunção, Paraguai. Legenda com modificações. 
1962 Tentaculites stubeli PUTZER (non CLARKE 1899) Geol. Erde; p. 60; est. 1; fig. 9.

1962 Tentaculites trombetensis PUTZER (non CLARKE 1899) Geol. Erde; p. 53; est. 2; fig. 9.

1972 Tentaculites sp. indet. (aff. T. crotalinus SALTER), HARRINGTON Geol. Soc. Amer., Spc. Pap.; v. $133 ;$ p. 44.

1972 Tentaculites $\mathrm{sp}$. indet. (=T. trombetensis WOLFART, non CLARKE, partim) HARRINGTON Geol. Soc. Amer., Spc. Pap.; v. 133; p. 44.

1972 Tentaculites sp. indet. ( $=T$. trombetensis WOLFART, non CLARKE, partim) HARRINGTON Geol. Soc. Amer., Spc. Pap.; v. 133; p. 44.

HOLÓTIPO: Prancha 1, (Foto a), espécime GP/1T 1441-D

DIAGNOSE: Concha coniforme, com região apical lisa; ápice liso, simétrico e abrupto com extremidade arredondada. Concha anelada da regiâo mediana à abertura, anéis e espaços interanelares regulares e com crescimento gradual e acentuado da saliência anelar. Anéis com cristas arredondadas e espaços interanelares lisos.

DESCRIÇÃO: Concha coniforme, anelada apenas a partir da região mediana até a abertura, onde se tem a possível ocorrência de opérculo. Os anéis e espaços interanelares normalmente são regulares; possuem espessura e espaçamento aproximadamente constantes, mas há um aumento gradual e acentuado da saliência dos anéis e concavidade dos espaços interanelares.

Região apical: $\quad$ Cônica e lisa, com ápice liso, simétrico e abrupto com extremidade arredondada. Parte inferior à média lisas, sem evidências anelares. Porção média à superior com suaves ondulações que aumentam gradualmente para a região mediana.

Regiāo mediana: Por passagem gradual da região ápical adquire feições anelares com pequenas saliências e espaços interanelares com baixa concavidade.

Região da abertura: Anelação e espaços interanelares adquirem feições salientes e gradualmente crescentes para a abertura. Anéis com cristas arredondadas, suavemente voltadas para a abertura. Os espaços interanelares são lisos com concavidade acentuada. $\mathrm{Na}$ abertura de um espécime tem-se a presença provável de opérculo.

DERIVAÇÃO DO NOME: "itacurubiensis", denominação dada com base na unidade litoestratigráfica Itacurubi, atualmente na categoria de grupo e sobreposta ao Grupo Caacupé.

MEDIDAS: Os espécimes analisados possuem comprimento menor que $10 \mathrm{~mm}$, com número de anéis variável para tentaculitídeos do mesmo tamanho. $\mathrm{O}$ ângulo apical varia de $5,5^{\circ}$ a $10^{\circ}$, evidenciando diferentes graus de compactação ou diferentes estágios de desenvolvimento ontogenético.

COMPARAÇÃO: Os tentaculitóideos mencionados na literatura paleontológica do Eopaleozóico como ocorrentes no Paraguai têm sido denominados $T$. crotalinus, $T$. jaculus, $T$. trombetensis e $T$. stubeli.

Tentaculites itacurubiensis difere de $T$. crotalinus SALTER, 1856 emend. Ciguel et al. (1984), por apresentar a regiảo apical lisa; anéis com cristas arredondadas; proeminência anelar saliente; espessura anelar e espaçamento interanelar constante; ângulo apical maior; e menor tamanho médio.

Tentaculites intacurubiensis possui afinidades morfologicas com Tentaculites trombetensis CLARKE, 1899. Espécimes de $T$. trombetensis, da Formação Trombetas, Siluriano da Bacia Amazonas, foram colocados à disposição do autor pelo Prof. Dr. C.S. Ferreira do Museu Nacional, Rio de Janeiro. A análise desses fósseis revelou feiçőes anelares e interanelares menos salientes que $T$. itacurubiensis. As duas espécies possuem afinidades genéricas, diferindo a nível específico, pela presença da regiâo apical lisa no tentaculitídeo paraguaio.

Tentaculites itacurubiensis difere de $T$. stubeli CLARKE 1899 por possuir anelação perpendicular ao eixo axial da concha, regularidade e saliência anelar.

Difere de T. jaculus CLARKE, 1913, segundo Ciguel et al. 1984, por apresentar anéis e espaços interanelares mais espessos e regulares; anelação saliente com espaços; e concavidade acentuada.

Difere de Tentaculites sp. 1 (Ciguel et al. 1984) por apresentar concha lisa na região apical; anéis com cristas arredondadas; saliência anelar proeminente; espessura anelar e espaçamento aumentando tênue e regularmente para a porção posterior da concha.

Difere de Tentaculites sp. 2 (Ciguel et al. 1984) por possuir região apical lisa e anéis com cristas arredondadas.

Difere de $T$. eldredgianus (HARTT \& RATHBUN), in Clarke 1899, pelo tipo de ornamentação anelar e região apical lisa.

Difere de $T$. oseryi CLARKE (1899) por apresentar aneis salientes e regulares com espessura e espaçamento interanelar tenuamente crescentes da região mediana à abertura.

Difere de $T$. antarcticus (FISCHER), in Doumani et al. 1965, pela presença de anéis com cristas arredondadas; maior saliência anelar e espaços interanelares; menor número de anéis e maior ângulo apical.

Tentaculites itacurubiensis difere ainda dos seguintes tentaculitídeos: de $T$. baini REED (1908) e $T$. desuetus REED (1925) pela ausência de estrias longitudinais; de $T$. canadensis (AMI), apud Mclearn (1924), por apresentar anéis salientes e espaços interanelares com alta concavidade; $T$. cartieri CLARKE (1907) por apresentar regiâo apical lisa e saliência anelar; de $T$. semilukianus (LJASCHENKO), apud Hajlasz et al. 1978, pela região apical lisa e regularidade nas regiōes mediana e da abertura; de $T$. gyrocanthus (EATON), apud Hajlasz (1974), por apresentar espaço interanelar liso, anéis e espaços interanelares regulares com aumento de saliência para a abertura; de T. scalaris (SCHLOTHEIN), apud Lardeux 1969, por apresentar a regiäo apical lisa.

Tentaculites cf. t. itacurubiensis ilustrado na figura 4, foto $\mathrm{g}$, difere de $T$. itacurubiensis devido à presença de anéis com espessura crescendo irregularmente a partir da região apical; espaçamento interanelar variável e irregular; e ângulo apical mais acentuado.

LOCALIDADE: As amostras contendo os tentaculitídeos foram coletados entre as latitudes de $25^{\circ}$ e $25^{\circ} 30^{\prime} \mathrm{S}$ e longitudes $57^{\circ} 30^{\prime}$ e $57^{\circ} \mathrm{W}$, no município de Itauguá. O afloramento denominado Cantera de Itauguá situa-se a aproximadamente 2 $\mathrm{K} m$ da cidade homônima.

POSIÇÃO ESTRATIGRÁFICA: Os Tentaculites paraguaios ocorrem na Formação Cariay (Fig. 3), representada por arenitos, e na Formação Vargas Peña, por folhelhos. Essas unidades pertencem ao Grupo Itacurubi juntamente com a Formação Eusebio Ayala.

MATERIAL ESTUDADO E REPOSITÓRIO: As amostras contendo cerca de uma centena de espécimes receberam os números GP/LT-1441 A-H; 1442; 1443; 1444; 1445; 1446 A-B; 1447 A-E; e 1448, e estão depositadas no Departamento de Paleontologia e Estratigrafia do Instituto de Geociências da Universidade de São Paulo, Brasil.

DISCUSSÃO: As unidades litoestratigráficas paraguaias que apresentam Climacograptus innotatus brasiliensis, Diplo- 


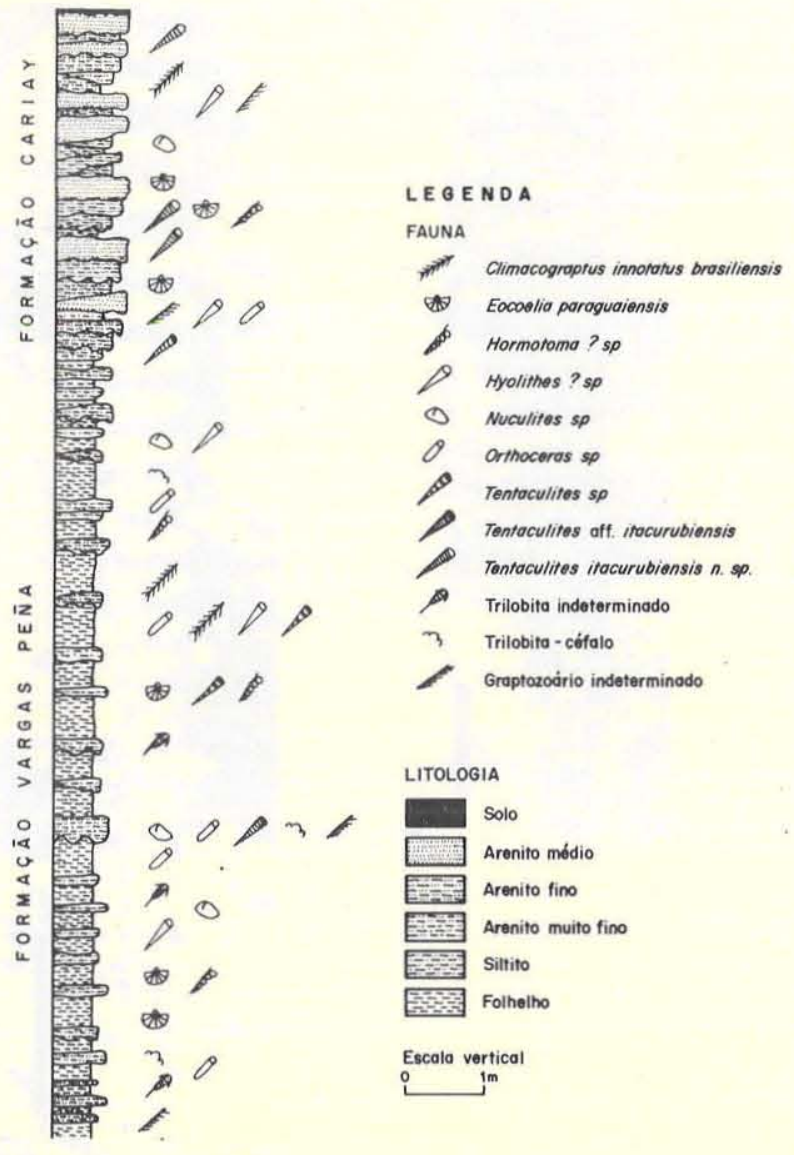

Figura 3 - Seção litoestratigráfica com a distribuição da tafocenose observada na Cantera Itauguá. Exposição das formações do topo do Grupo Itacurubi, exibïndo contato transicional.

sraptus modestus ou Arthrophycus alleghaniensis, como componentes da fauna, têm sido consideradas como de idade siluriana, possivelmente Llandoveriano (Siluriano Inferior). No Brasil, as formaçöes Trombetas e Vila Maria, e no Paraguai as formações Eusebio Ayala, Vargas Peña e Cariay têm sido correlacionadas com base em seu conteúdo fossilífero ou icnofossilifero. Turner (1960) identifica a presença de Diplograptus modestus LAPWORTH e Climacograptus innotatus brasiliensis RUEDEMANN nos folhelhos Vargas Peña e arenitos Cariay, e concorda com a idade eollandoveriana (Valentiano) aventada por Harrington (1950). Ruedemann (1929), com base em $C$. innotatus brasiliensis, correlaciona a Formação Trombetas com o Andar Medinano, tal como Derby (1878), que se baseia na presença de Arthrophycus alleghaniensis. Clarke (1899), interpreta este icnofossil e demais elementos da fauna da localidade-tipo da Formação Trombetas da seguinte forma: seis não indicam idade, oito indicariam a idade neo-ordoviciana e nove caracterizariam uma fauna siluriana, com duas ocorrendo no Andar Medinano, três no Clintoniano e quatro no Niagarano. Para esse autor, e também Derby (1878), a Formaçåo Trombetas possui idade eollandoveriana. Para Lange (1967), essa formação, em sua porção basal, poderia ser mais antiga.

Wolfart (1961) considera a idade eollandoveriana para o
Grupo Itacurubi, com base na ocorrência de Arthrophcus alleghaniensis e C. innotatus brasiliensis, além de correlacioná-la com a Formação Trombetas. Burjack \& Popp (1981) consideram a mesma idade para a Formação Vila Maria devido a ocorrência da referida icnoespécie.

Jackson \& Lens (1962) mencionam a presença de Climacograptus innotatus, relacionado à subespécie brasiliensis, no Ordoviciano Superior (Ashgilliano) dos estratos canadenses das Montanhas Ogilvie. Ruedemann (1947) descreve duas subespécies de $C$. innotatus para o Ordoviciano Superior da América do Norte (EUA). Segundo Lange (1972), a presença de $C$. innotatus brasiliensis no Paraguai, associado a outras espécies, indica a idade eollandaveriana, até para a porção basal da Formação Trombetas. Na América do Norte ocorrem subespécies de $C$. innotatus no Ordoviciano Superior, enquanto nas Ilhas Britânicas ocorrem em camadas do Llandoveriano Inferior.

Baldis \& Hansen (1980), com base na homologia entre os trilobitas paraguaios a Eohomalonotus, ocorrente na pré-cordilheira da Argentina, aventam a idade neo-ordoviciana (Ashgilliano) para a Formação Cariay. Esta pode atingir o Ordoviciano Médio (Llanvirniano), pois sua fauna de trilobitas já apresenta as primeiras características austrais, uma vez que essa diferenciação teria ocorido a partir do Llanvirniano.

A distribuição do icnofossil cosmopolita A. alleghaniensis, segundo Aceñolaza (1978), se dá entre o Ordoviciano e Siluriano; para Häntzschell (1962), ocorre no Siluriano, podendo atingir o Devoniano. Conforme Borello (1966), sua distribuição se estenderia do Ordoviciano ao Siluriano. Portanto, o posicionamento de unidades litoestratigráficas com base nesse icnofossil deve ser cauteloso, visto que sua distribuição está situada entre o Ordoviciano e provavelmente Devoniano Inferior.

A presença de Climacograptus innotatus brasiliensis $e$ Diplograptus modestus não permite um posicionamento categórico no Llandoveriano. A fauna do Grupo Itacurubi já exibe as primeiras características malvinocáfricas do Siluriano, além de o registro fossilífero dos graptozoários a nível mundial se dar a partir do Ordoviciano.

A situação geotectônica dos sedimentos pós-ordovicianos e pré-devonianos no Paraguai assim como seu posicionamertlo tectono-estratigráfico sugerem idade mais recente que o Ordoviciano Inferior. Conseqüentemente, os depósitos pericratônicos do Eopaleozбico no Paraguai oriertal são posteriores ao Tremadociano (Ordoviciano Inferior), pois não foram afetados pelos últimos espasmos do Ciclo Brasiliano.

Fisher (1962) refere duvidosamente a Família Tentaculitidae como distribuindo-se do Siluriano ao Devoniano Superior (Frasniano), na América do Sul. Lardeux (1969), com base na distribuição da Ordem Tentaculitida na Europa, Ásia e África do Norte, menciona a ocorrência de tentaculitídeos entre o Siluriano e Devoniano (Frasniano) e provavelmente Ordoviciano Inferior (Tremadociano). Tentaculites itacurubiensis ocorre na Formação Cariay, a qual é incluída por Elles \& Wood (1918), modificado por Berry \& Boucot (1972), na Zona Monograptus gregarius, cuja idade corresponderia a parte inferior do Mesollandoveriano.

CONCLUSÕES: A posição tectono-estratigráfica dos depósitos pericratônicos do Paraguai oriental, associada à presença de Climacograptus innotatus brasiliensis, Diplograptus modestus, Monograptus gregarius, Arthrophycus alleghaniensis, homologia entre os trilobitas paraguaios e Eohomalonotus, e a associação faunística com tendências a Província Malvinocáfrica siluriana permitem aventar uma idade para 

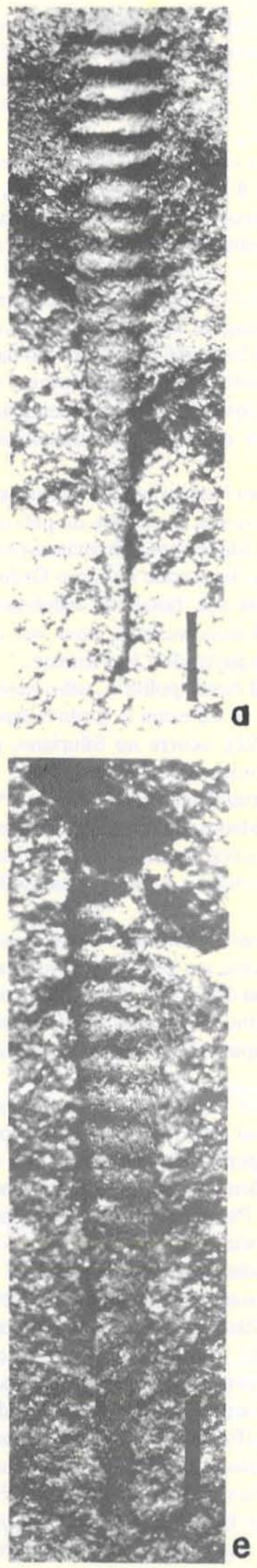
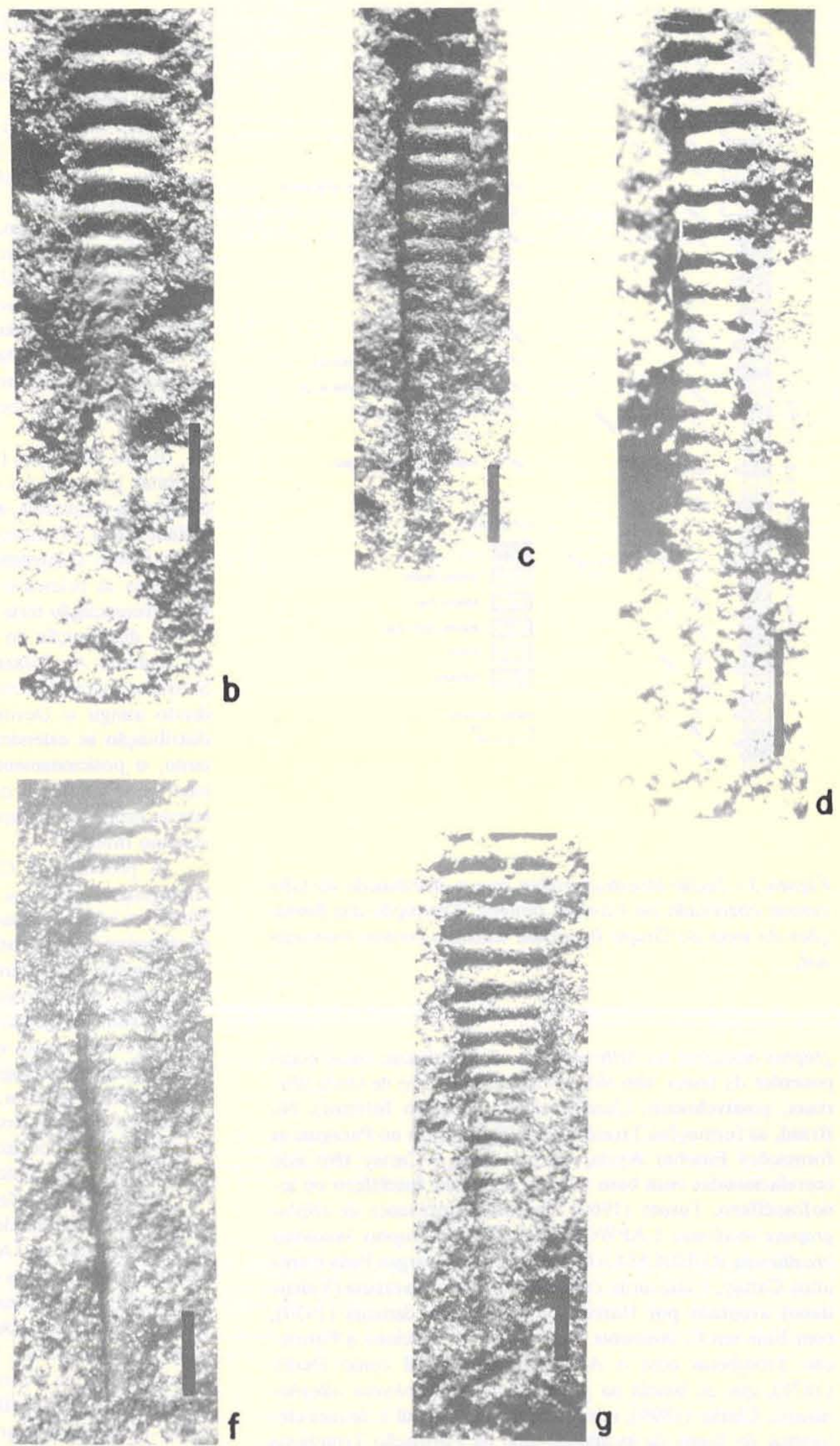

Prancha1- Tentaculites itacurubiensis n. sp., ocorrente na Formação Cariay (Grupo Itacurubi), Paraguai oriental. O molde externo dos espécimes é observado em vista frontal, superior, paralelo ao plano de acamamento dos arenitos. Escala = $1 \mathrm{~mm}$. Fotos a. Região da abertura apresentando anéis e espaços interanelares lisos. Região mediana com anelação tênue. Espécime com região apical lisa; b. Coniconchia, com região apical lisa. Região mediana com ondulações, que adquire feição anelar na região da abertura; c. tentaculittdeo, anelado a partir da porção superior da região apical; $\mathbf{d}$. tentaculitideo coniforme, anelado a partir da porção superior da região apical. Espaços interanelares lisos; e. espécime exibindo baixa saliência anelar; f. Coniconchia, anelado a partir da região mediana. Região apical lisa, com ápice simétrico e abrupto; $e$ g.Tentaculites cf. Tentaculites itacurubiensis.Esse coniconchia exibe ângulo apical acentuado e anéis com espessura e distância variável ao longo do eixo da concha 
esses depósitos situada do Ordoviciano Médio ao Superior (Grupo Caacupé e base do Grupo Itacurubi) e Siluriano Inferior para o Grupo Itacurubi. Contudo as dataçöes dessas unidades litoestratigráficas e das brasileiras, situadas entre o Ordoviciano e Siluriano com base nesses fosseis e icnofosseis, ou ambos, não devem ser consideradas definitivas.

Das três ordens da Classe Tentaculitoidea, Tentaculitida é representada por espécimes com maior simplicidade da concha, que se distribuem do Ordoviciano ao Devoniano. As ordens Homoctenida e Dacryoconarida possuem conchas com ornamentação complexa e ocorrem predominantemente no Devoniano. Tentaculites itacurubiensis caracteriza-se pela simplicidade na ornamentação da concha.

A ocorrência de $T$. trombetensis CLARKE, 1899 e $T$. itacurubiensis n. sp. na Formação Cariay permite estender, de forma efetiva, a distribuição estratigráfica da Ordem Tentaculitida ao Llandoveriano, na América do Sul.

O posicionamento cronoestratigráfico do Grupo Caacupé está diretamente relacionado ao Grupo Itacurubi. Com base nessas relaçöes, os depósitos do Grupo Caacupé estão situados entre a porção superior do Ordoviciano Inferior e Ordoviciano Médio, interdigitando-se no Ordoviciano Superior com os depositos do Grupo Itacurubi.

O grupo basal estaria representando um ambiente deposicional transicional entre o marinho e o continental, princi- palmente sob a influência litorânea. No Grupo Itacurubi, o topo da Formação Eusebio Ayala representaria um ambiente marinho raso, caracterizando regiōes litorâneas, onde se tem a presença de icnofósseis do tipo Skolithos. A formação sobreposta, Vargas Peña, com sua típica fauna marinha, representaria o maior evento transgressivo do Paraguai oriental, e a formação Cariay marca a início da regressão, com a fauna marinha desses arenitos constituindo uma tafocenose típica.

Agradecimentos: Ao Dr. J.A. Palmieri (Ministério de la Defensa del Paraguay), Prof. Dr. A. Florentin e Prof. A.D. Romero (Universidad Nacional de Asunción), por facilitarem a realização do presente trabalho. Da Universidade Federal do Paraná (UFPR), aos professores Dra. R.D. Becker, Dr. J.J. Bigarella, Dr. A.V. Bittencourt e Dr. E. Trein, pelo auxílio e sugestões. Do Instituto de Geociências, Universidade de São Paulo (IG-USP), aos professores Dr. T.R. Fairchild, pelas críticas e sugestões que visaram a melhoria do Abstract. Aos Drs. S. Petri e O. Rösler pelos comentários, sugestőes, esclarecimentos e estímulo. Ao Dr. V.J. Fúlfaro, da Universidade Estadual de São Paulo, Rio Claro (Unesp), pelos comentários. À Dra. A.M.C. Clérici (Piribebuy, Paraguai), pelo auxillio na elaboração das seções estratigráficas. Aos amigos J.R. G6is (Mineração Jorupegi) e R. Rohn (IG-USP) pela colaboração e auxílio. Ao Dr. C. S. Ferreira, Museu Nacional, Rio de Janeiro, a minha admiração.

\section{REFERÊNCIAS BIBLIOGRÁFICAS}

ALCEÑOlAZA, F.G. 1978. El Paleozoico inferior da Argentina segunsus trazas fosiles. Ameghiniana, Buenos Aires, 15(1/2):1564.

BALDIS, B.A.J. \& HANSEN, H. 1980. Trilobites dalmanítidos de Paraguay Oriental. In: CONGR. ARGENT. PALEON. Y BIOESTRAT. 2 e CONGR. LATINOAMER. PALEON., 1, Buenos Aires, 1978. Actas... Argentina, Asoc. Paleontol. Argent. v. 1 , p. $49-67$.

BEDER, R. \& WINDHAUSEN, A. 1918. Sobre la presencia del Devónico en la parte media de la República del Paraguay. Bol. Acad. Nac. Cien., Córdoba, 23:255-262.

BERRY, W.B.N. \& BOUCOT, A.J. 1972. Correlation of the south American Silurian rocks. Geol. Soc. Americ., Spec. Pap., Boulder, (133):1-3.

BORRELlO, A.V. 1966. Las facies de Cruziana en el Ordovicico del norte Argentino. Ameghiniana, Buenos Aires, 4(6):185-188.

BOUCOT, A.J. \& CASTER, K.E. 1984. First occurence of Scaphiocoelia (Brachiopoda; Terebratulida) in the early Devonian of the Paraná Basin, Brazil. J. Paleont., Tulsa, 58(6):1354-1359.

BURJACK, M.I.A. \& POPP, M.T.B. 1981. A ocorrência do icnogênero Arthrophycus no Paleozóico da Bacia do Paraná. Pesquisas, Porto Alegre, 14:163-168.

CIGUEL, J.H.G.; RÖSLER, O.; CAMINERO, D. 1984. Tentaculitoidea da Formação Ponta Grossa no Estado do Paraná. In: CONGR. BRAS. GEOL. 33, Rio de Janeiro, 1984. Anais... Rio de Janeiro, SBG. v. 2, p. 655-669.

CLARKE, J.M. 1899. A fauna Siluriana Superior do Rio Trombetas, Estado do Pará, Brazil. Arch. Mus. Nac., Rio de Janeiro, 10:148.

CLARKE, J.M. 1907. Some New Devonic Fossils. Bull. New York State Mys. 107(Geology 12):153-291.

CLÉRICE, A.M.V.C. 1986. Reavaliação da Geologia do Paraguai Oriental. São Paulo (Tese Dout. IGUSP).

DERBY, O.A. 1878. Contribuição para a Geologia da Região do Baixo Amazonas. Arch. Mus. Nac, , Rio de Janeiro, 2:77-104.

DOUMANI, G.A. et al. 1965. Lower Devonian Fauna of the Horlick Formation, Ohio Range, Antarctiva. Geology and Paleontology of the Antarctic. American Geophysical Union. Columbia, 6(1299):241-274.
ELLES, G.L. \& WOOD, E.M.R. 1918. A monograph of british graptolites. Paleontographical Soc., London, 70:782-839.

FISHER, D.W. 1962. Small conoidal shells of uncertain affinities In: MOORE, R.C. ed. Treatise on invertebrate paleontology. New York, Geol. Soc. Amer, p. 98-143. (Part W, Miscellanea).

HAJKASZ, B. 1974. Tentaculites of the upper Silurian and Lower Devonian of Poland. Acta Palaeontol. Pol., Warszawa. 19(4): 455-500.

HAJASZ, B.; MASSA, D.; BONNEFOUS, J. 1978. Silurian and Devonian Tentaculites from Libya and Tunisia. Bull. Cent. Rech. Explor. Prod. Elf-Aquitaine, Pau, 2(1):1-37.

HÄNTZCHEL, W. 1962. Trace fossils and problemativa. In: MOORE, R.C. ed. Treatise on invertebrate paleontology. New York, Geol. Soc. Amer. p. 177-245. (Part W, Miscellanea).

HARRINGTON, H.J. 1950. Geología del Paraguay Oriental. Fac. Cienc. Exact. Contr. Ciênc. Sec. E, Geol., Buenos Aires, 1:1-82.

HARRINGTON, H.J. 1956. Paraguay. Memoir. Geol. Soc. Am. Boulder, (65):99-114.

HARRINGTON, H.J. 1972. Silurian of Paraguay. Geol. Soc. Am., Spec. Pap., Boulder, (133):41-50.

JACKSON, D.E. \& LENZ, A.C. 1962. Zonation of Ordovician and Silurian graptolites of northern Yukon, Canada. Bull. Am. As. soc. Petroleum Geologists, Tulsa, 46(1):30-45.

LANGE, F.W. 1967. Subdivisão bioestratigráfica e revisão da coluna siluro-devoniana da bacia do baixo Amazonas. In: SIMP. SOBRE A BIOTA AMAZÔNICA, 1967. Atas... Geociências. v. 1, p. 215-326.

LANGE, F.W. 1972. Silurian of Brazil. Geol. Soc. Americ., Spec. Pap., Boulder, (133):33-39.

LARDEUX H. 1969. Les Tentaculites d'Europe occidentale et $d$ Afrique du nord. Paris, Cent. Nat. Rech. Sci., 238 p. LII Pranches, (Cahiers de Paléontologie).

McLEARN, F.H. 1924. Paleontology of the Silurian Rocks of Arisaig, Nova Scotia. Memoir. Geological Survey of Canada, Boulder, 137(118):1-180.

NORTHFLEET, A.; MEDEIROS, R.A.; MUHLMANN, H. 1969. Reavaliação dos dados geológicos da Bacia do Paraná. Bol. Tec. Petrobrás, Rio de Janeiro, 12(3):291-346. 
PUTZER, H. 1962. Geologie von Paraguay. Beitrage zur Regionalen, Geologie der Erde., 2:183 p.

REED, F.R.C. 1908. Mollusca from the Bokkeveld Beds. Annals of the South African Museum, Cape Town, 4(6):245-247.

REED, F.R.C. 1925. Revision of the fauna of the Bokkeveld Beds. Annals South African Museum, Cape Town, 22:27-225.

RUEDEMANN, R. 1929. Descrição dos graptólitos do Rio Trombetas. Rio de Janeiro, Mon. Serv. Geol. Min. p. 20-24. (Mon. 7).

RUEDEMANN, R. 1947. Graptolites of North America. Memoir The Geological Society of America, Boulder, (19):1-652.
TURNER, J.C.M. 1960. Faunas graptolíticas de América del Sur. Rev. Asoc. Geol. Argentina, Buenos Aires, 14(1/2):1-180.

WOLFART, R. 1961. Stratigraphie und fauna des älteren Paläozoikunms (Silur, Devon) in Paraguay. Geologisches Jahrbuch, Hannover, 78:29-102.

MANUSCRITO 412

Recebido em 12 de dezembro de 1986 Revisão aceita em 17 de dezembro de 1986

\section{NOTÍCIAS}

\section{CTC de GEOTECTÔNICA}

A Comissão Ténico-Cientiffica de Geotectônica da SBG convida a todos os profissionais atuantes no ramo para se afiliarem a CTC. A Diretora nomeada para o biênio 87/89 pretende realizar uma gestão em que a participação dos afiliados seja a maior possível.

Para tanto, está em estudo a implantação de um "boletim" da CTC, que será o veículo natural de implementação deste objetivo. Sugestőes, nesta fase inicial de reorganizaço da Comissẩo, serão extremamente bem-vindas. Escreva para:

\section{CTC de Geotectônica da SBG \\ A/C: EDISON JOSÉ MILANI - Presidente \\ PETROBRÁS/DEPEX/SENORT \\ Av. Chile, 65 - $13^{\circ}$ Andar \\ 20.035 - Rio de Janeiro - RJ}

No aludido "boletim", pensa-se incluir, num freqüência semestral, assuntos tais como:

- Eventos em realização no país, relacionados à área;
- Análise de publicações recentes, realizadas por profissionais destacasos, a serem convidados;

- Discussão em torno do ensino da Geotectônica e da Geologia Estrutural na graduação de Geologia no Brasil;

- Resumos de artigos técnicos publicados em periódicos internacionais;

- Comentários em torno de afloramentos selecionados em diversos pontos do país, a serem elaborados por profissionais conhecedores da área (fotos e comentários).

DIRETORIA DA CTC - Biênio 87/89

EDSON JOSÉ MILANI - Presidente

PETROBRÁS/Depto. de Exploração

IAN DAVISON - Vice-Presidente

UFBA/Pós-Grad. em Geologia

MARCO AURÉLIO LEMOS LATGÉ

PETROBRÁS/Depto. de Exploração 